\title{
COLONY SEX RATIOS IN THE FACULTATIVELY POLYGYNOUS ANT PHEIDOLE PALLIDULA: A REANALYSIS WITH NEW DATA
}

\author{
Ken R. Helms, ${ }^{1}$ Denis Fournier, ${ }^{2}$ Laurent Keller, ${ }^{3}$ Luc Passera, ${ }^{4}$ And Serge Aron ${ }^{2}$ \\ ${ }^{1}$ Department of Entomology, Entomology Research Laboratory, Texas A\&M University, College Station, Texas 77843-2475 \\ E-mail:khelms@neo.tamu.edu \\ ${ }^{2}$ Department of Animal Biology, Behavioral and Evolutionary Ecology, Université Libre de Bruxelles, Avenue F.D. Roosevelt, \\ 50, B-1050 Brussels, Belgium \\ ${ }^{3}$ Department of Ecology and Evolution, University of Lausanne, Biology Building, 1015 Lausanne, Switzerland \\ ${ }^{4}$ Laboratory of Ethology and Animal Cognition, University Paul-Sabatier, 118, route de Narbonne, F-31062 Toulouse, France
}

\begin{abstract}
A recent study by Fournier et al. (2003) provides important new information on sex allocation in the ant Pheidole pallidula, and proposes a new scenario for sex-ratio evolution in P. pallidula and similar species. However, Helms proposed to the authors that two important conclusions of the study were questionable because of potential problems with the analyses. Here we provide new data and a reanalysis that strengthens the conclusion that colony sex ratio is associated with breeding system (i.e., polygyny or monogyny). However, the proposal that colonies shift from monogyny to polygyny when they become larger and more productive is weakened because there is substantial overlap in productivity between monogynous and polygynous colonies.
\end{abstract}

Key words._-Ants, colony productivity, Pheidole pallidula, queen-worker conflict, sex ratio.

Received November 6, 2003. Accepted February 2, 2004.

Fournier et al. (2003) inferred colony size from productivity, which was estimated from the biomass of sexual broods, a procedure often used in other studies (e.g., Aron et al. 1999). However, Helms suggested that a corrected version of biomass would have been more appropriate. Earlier studies of ants and other aculeate Hymenoptera have shown that estimates of sexual productivity from biomass can substantially overestimate the cost of producing reproductive females relative to males, with that overestimation increasing with increasing female relative to male mass (Boomsma 1989; Helms 1994; Boomsma et al. 1995). A correction of $\left(W_{f} / W_{m}\right)^{0.7}$, where $W_{f}$ is the dry mass of a female and $W_{m}$ is the dry mass of a male, was proposed as a general solution for the problem in ants (Boomsma 1989). In P. pallidula, a reproductive female weighs about seven times (6.98) more than a male (Keller et al. 1996). However, applying Boomsma's (1989) correction, they are estimated to require only about four times (3.90) as much energy to produce. As a result, estimates of colony productivity in Fournier et al. (2003) could have greatly overestimated energetic expenditure of polygynous colonies because they produced mostly females whereas monogynous colonies produced mostly males (Fig. 1 in Fournier et al. 2003).

The second problem raised by Helms was that Fournier et al. (2003) excluded from analyses nine colonies that produced fewer than 20 reproductives. This was motivated by the fact that a small number of reproductives may not give a reliable estimate of colony sex ratio. However, in this case, it is problematic. A $P$. pallidula colony producing 19 females produces a sexual biomass of $116.7 \mathrm{mg}$, whereas a colony producing 19 males produces a sexual biomass of only $16.7 \mathrm{mg}$ (Keller et al. 1996). In the data of Fournier et al., 13 of 16 monogynous colonies (producing mostly males) produced a reproductive brood of less than $116.7 \mathrm{mg}$. Given the data exclusion rule utilized by Fournier et al. (2003), any femaleproducing colony overlapping in sexual productivity with most of the male-producing colonies would be excluded from analysis, resulting in elevated estimates of the relative productivity of female-producing colonies.

In our reanalysis, colony productivity was estimated as both the biomass of sexual brood (as originally presented), and the corrected version (Boomsma 1989). For the nine colonies that produced fewer than 20 reproductives, Fournier et al. determined, as for the other colonies, the number of functional queens per colony by genotyping 10 workers per colony at four microsatellite loci (see methods in Fournier et al. 2003). The inclusion of these additional colonies in the new analyses had two consequences.

First, the relationship between the presence of one or more queens per colony and sex ratio is strengthened. Of the nine colonies with low productivity, eight were polygynous and produced only females, whereas one colony was monogynous and produced only males. Thus, overall, 13 of the 14 malespecialist colonies were monogynous and all 17 female-specialist colonies were polygynous (Fisher's exact test of independence, $P<0.0001)$. The four colonies producing both sexes were monogynous.

The second consequence is that the relationship between queen number and productivity is weakened, although it remains significant. In the original analysis, polygynous colonies were 4.8-times more productive than monogynous colonies (6.8-times based on median values; Fournier et al. 2003). Without applying the correction to the new biomass data, polygynous colonies are substantially less productive, with median productivity of polygynous colonies being 2.7times greater than monogynous colonies (Mann-Whitney Test: $T=204, P<0.001)$. Applying the correction further decreases the difference, with median productivity of polygynous colonies being 1.6-times greater than monogynous colonies (Mann-Whitney Test: $T=246, P=0.046$ ). Other results are consistent with the original analyses. There is no significant association between colony sex ratio and queen 

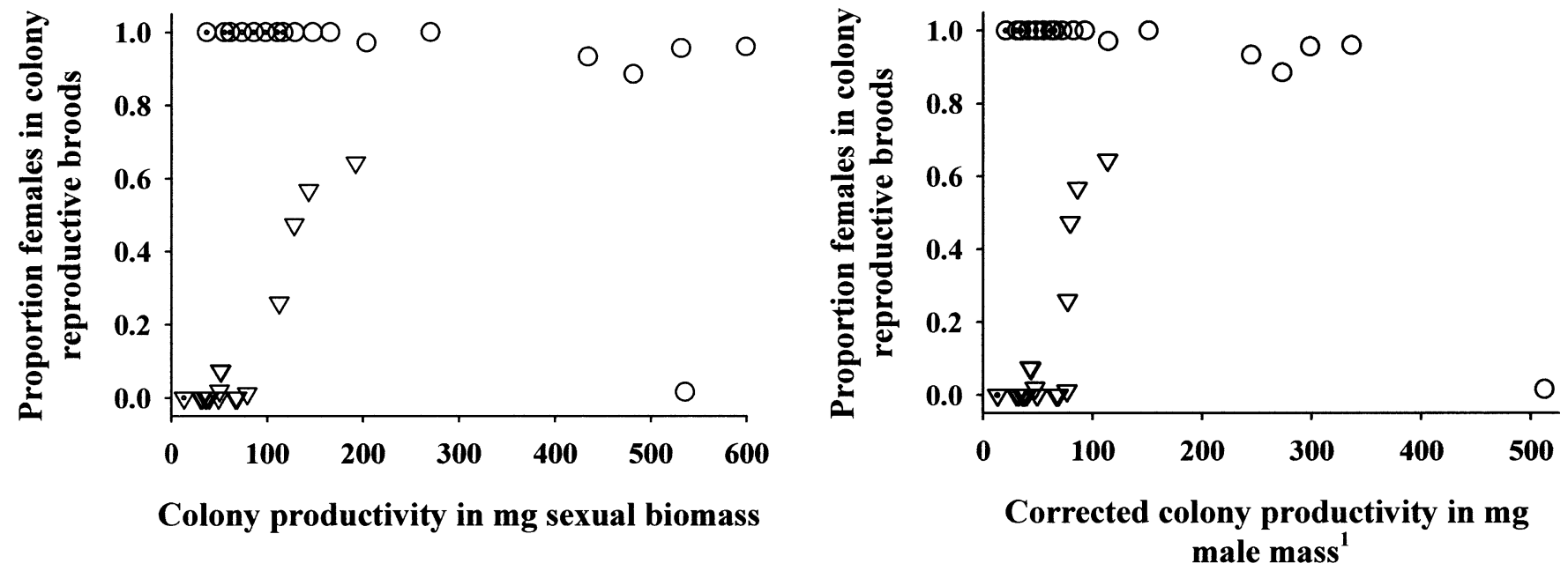

FIG. 1. Colony sex allocation as a function of colony productivity in Pheidole pallidula colonies studied by Fournier et al (2003). (Left) The raw data, in which sexual productivity is determined by biomass of the sexual broods. (Right) The data after applying a correction for female versus male biomass-specific energetic cost (see footnote 1). Circles indicate polygynous colonies, whereas triangles indicate monogynous colonies. Dotted symbols indicate data excluded in the analyses of Fournier et al. (2003). ${ }^{1}$ Estimated reproductive productivity following correction for differences in female versus male energetic cost per unit biomass (Boomsma 1989). This was estimated for each colony by: $\left[\left(\bar{W}_{f} / \bar{W}_{m}\right)^{0.7} \cdot F \cdot \bar{W}_{m}\right]+\left(M \cdot \bar{W}_{m}\right)$, where $F$ is the number of females produced and $M$ is the number of males produced, $\bar{W}_{m}$ is the average biomass of a male $(0.88 \mathrm{mg})$ and $\bar{W}_{f}$ is the average biomass of a female $(6.14 \mathrm{mg})$.

number in polygynous colonies (Spearman rank correlation: $\left.r_{s}=-0.19, P>0.4\right)$, and there remains a significant increase in the proportion of females in the reproductive brood of monogynous colonies with increasing colony productivity (Fig. 1; uncorrected data: $r_{s}=0.79, P<0.001$; corrected data: $\left.r_{s}=0.73, P<0.001\right)$, Spearman rank correlation). Queen number in polygynous colonies ranges from two to four (harmonic mean $=2.2$ ).

The perfect association between queen number and sexratio specialization in colonies originally excluded from analyses further strengthens the conclusion of Fournier et al. (2003) that the breeding system of colonies is strongly correlated with colony sex ratio. However, the inclusion of these colonies greatly influenced the relationship between colony productivity and breeding system. The new analysis reveals considerable overlap between productivity of monogynous and polygynous colonies (Fig. 1), and the pattern of a transition from small monogynous colonies producing males to large polygynous colonies producing females, is no longer clearly evident. Importantly, our reanalysis demonstrates that queen number and not overall productivity is the main factor affecting colony sex ratio.

Based on a suggestion of David Queller, Fournier et al. (2003) proposed that the strong association between breeding system and colony sex ratio might result from a "tragedy of the commons", whereby competition among queens in polygynous colonies prevents them from limiting female egg availability. Under this scenario, queens in monogynous colonies would limit the number of female eggs, thus forcing workers to raise males. In contrast, competition among queens over egg production in polygynous colonies would result in an overabundance of eggs and enable workers to manipulate the sex ratio to their own advantage (Fournier et al. 2003). However, because the reanalysis shows that colony productivity does not appear to increase $1: 1$ with queen num- ber, it should be noted that the presence of multiple queens, each producing eggs at the rate at which they do so in monogynous colonies, should increase egg availability in polygynous colonies. Whether it would be enough to initiate the evolution of split sex ratios as proposed, or whether it requires a shift in queen egg production that depends upon colony social organization, remains to be tested. As noted by Fournier et al. (2003), further study is clearly needed to understand the evolutionary causes of the strong association between breeding system and colony sex ratio in this interesting ant.

\section{ACKNOWLEDGMENTS}

We thank A. F. G. Bourke, R. Harrison, D. C. Queller, and an anonymous reviewer for helpful comments on earlier versions of the manuscript.

\section{Literature Cited}

Aron, S., E. Campan, J. J. Boomsma, and L. Passera. 1999. Social structure and split sex ratios in the ant Pheidole pallidula. Ethol. Ecol. Evol. 11:209-227.

Boomsma, J. J. 1989. Sex-investment ratios in ants: has female bias been systematically overestimated? Am. Nat. 133:517-532.

Boomsma, J. J., L. Keller, and M. G. Nielsen. 1995. A comparative analysis of sex-ratio investment parameters in ants. Funct. Ecol. 9:743-753.

Fournier, D., L. Keller, L. Passera, and S. Aron. 2003. Colony sex ratios vary with breeding system but not relatedness asymmetry in the facultatively polygynous ant Pheidole pallidula. Evolution 57:1336-1342.

Helms, K. R. 1994. Sexual size dimorphism and sex ratios in bees and wasps. Am. Nat. 143:418-434.

Keller, L., S. Aron, and L. Passera. 1996. Internest sex-ratio variation and male brood survival in the ant Pheidole pallidula. Behav. Ecol. 7:292-298.

Corresponding Editor: R. Harrison 